\title{
ENTREVISTA
}

\section{Henry Mintzbero}

enry Mintzberg, professor na McGill University, em Montreal, é hoje um dos nomes mais proeminentes no universo acadêmico da administração. Mundialmente conhecido por seus trabalhos sobre estratégia, poder e estrutura organizacional, recentemente firmou-se como crítico contumaz da formação executiva à americana, especificamente dos programas de MBA. Nesta entrevista, ele fala sobre o que está errado com a formação executiva e com o jeito norte-americano de administrar.

por Carlos Osmar Bertero e Pedro F. Bendassolli FGKEAESP

O senhor tornou-se mundialmente conhecido por suas críticas ao modo como atual mente funcionam as escolas de negócios e a educação executiva no mundo ocidental. Em linhas gerais, em sua opi nião, o que não vai bem com essas escol as?

Em primeiro lugar, não parece haver muita garantia de que os estudantes com os quais lidam as escolas de negócios sejam as pessoas certas. Ou seja, tenho muita dúvida (e há muita evidência para isso) sobre se esses estudantes têm habilidades de liderança ou mesmo sobre se eles desejam ser líderes. Alguns desejam, é claro; e alguns possuem aquelas habilidades. Contudo, receio que as técnicas de seleção 
dos estudantes, como o GMAT, por exemplo, não captam, necessariamente, a situação real do repertório desses estudantes. Cito, em meu livro (sobre MBA), o livro deDavid Ewing, Inside the Harvard Business School, de 1990, em que ele lista os dezenove melhores alunos dessa escola naquela época. Quando vejo na lista o nome de um Frank Lorenzo, digo para mim mesmo que há al guma coisa estranha aqui, pois se acompanharmos a trajetória daquelas pessoas, entre 1990 e 2003, por exemplo, veremos que dez, dentre elas, foram fiascos completos; quatro, tiveram um sucesso bastante questionável; e apenas cinco, entre eles Lou Gerstner, obtiveram resultados inequívocos. Não se deveria permitir que alguém como Lorenzo, que teve grandes derrocadas com três companhias aéreas e que continua com problemas com seus empregados, tocasse qualquer negócio, pois ele não possuía as verdadeiras habilidades de liderança, embora tivesse muitas habilidades de manipulação financeira.

\section{O senhor di ria que se trata de pessoas erradas no lugar certo ou de pessoas erradas no lugar errado?}

Entendo que há pessoas erradas nos programas de

MBA. Esses programas parecem atrair pessoas que eu caracterizaria como sendo impacientes, agressivas e interesseiras. Nem todas, mas um número considerável. Esse é um dos problemas com o público das escolas de negócio. 0 outro é que, mesmo que as pessoas fossem as certas, mesmo assim poderiam estar no momento errado, pois foram treinadas para serem líderes quando não sabiam nada de liderança. A conseqüência é que elas obtêm uma visão distorcida da liderança e assim tornam-se as pessoas erradas.

\section{O senhor, em seus escritos} sobre o tema, parece tocar em um ponto mais profundo da formação executiva. A questão é: seria possível realmente ensinar administração, ou, mais especificamente, ensinar as pessoas a serem líderes?

Para responder a esta questão, temos de entender que uma profissão é um corpo codificado de conhecimentos. Para praticá-la o indivíduo precisa ser treinado e certificado. Tome o exemplo da medicina. Sabemos em que condições e circunstâncias uma cirurgia será bemsucedida. Considere ainda o caso da engenharia: sabemos quais materiais são melhores para a construção de uma ponte. Na prática, isso quer dizer que tais coisas podem ser ensinadas antes de a prática ocorrer. Mas não é esse o caso com a administração - ela não tem um corpo de conhecimentos total mente codificado, tampouco um sistema de certificação que garanta que as pessoas são ou serão bons gestores ou líderes. Para falar a verdade, é o contrário que acaba ocorrendo, como no caso da certificação mais comum que temos hoje: o MBA. Temos grandes gestores que não gastaram um dia sequer em um programa executivo. Em compensação, não temos um bom cirurgião que não tenha gastado muitos anos numa escola de medicina, ou ainda bons engenheiros que jamais tenham lido algo sobre física. Assim, a idéia da administração como uma profissão não se sustenta.
Não há nenhum aspecto da administração que se encaixe em um esquema de qualificação profissional. Física e química são ciências no sentido forte do termo; administração não é uma ciência: sua preocupação não é encontrar a verdade.

\section{A administração não seria, como se costuma pensar normalmente, uma forma de "ciência aplicada"? \\ Não creio. Para mim, a admi- \\ nistração não é nem mesmo} uma "ciência aplicada", pois esta aqui ainda é uma ciência. A administração é a aplicação da ciência, entre outras coisas. Gestores usam tudo o que eles podem de um jeito prático, objetivando fazer as coisas acontecerem ou encorajar outras pessoas a fazerem as coisas acontecerem. Quero dizer com isso que a administração é uma espécie de artesanato. Ou seja, ela depende da experiência, da aprendizagem de campo. Coloco isso da seguinte forma: a administração tem muito mais a ver com pensar depois de ter feito algo do que com pensar primeiro, e depois fazer.

Mas se aceitarmos essa sua premissa, de que liderança não se ensina - ao menos não da forma como as escolas de negócios e seus al unos esperariam -, o que efetivamente podem fazer as escolas de negócio?

Hoje, uma escola de negócios típica está preocupada com as funções administrativas, e não com liderança. É obvio que os gestores devem dominar as funções de marketing, finanças, vendas e assim por diante. Contudo a prática de 
negócios não é a mesma coisa que a prática da gestão. Misturar essas funções todas numa mesma pessoa não é garantia de que ela vai se tornar um líder. Entendo que, ao mesmo tempo em que as escolas de negócios são bem-sucedidas em analisar coisas, separando-as em funções especializadas, elas não são bem-sucedidas em aglutinar coisas, sintetizando-as em uma visão coerente ou num sistema integrado. Em meu livro sobre os programas de MBA, comparo dois modos de conceber esta síntese. 0 primeiro é dado pelo "modelo Ikea": as escolas oferecem as partes e os estudantes montam o conjunto. Infelizmente, não há um manual de instruções e, infelizmente para o estudante, embora as partes pareçam estar cuidadosamente arrumadas para se encaixarem, elas não se ajustam umas às outras. A gestão, no mundo real, é muito mais parecida com as peças de um jogo Lego. Não há um único modo de juntar as peças, e é preciso tempo para que se construam estruturas interessantes.

\section{Essa ênfase das escolas de negócio em análise de} funções administrativas não poderia ter a contrapartida de estimular nos alunos uma falsa crença de que liderança e gestão se resolvem com fórmulas prontas?

De fato. 0 maior problema desse foco em análise de processos administrativos é que ele conduz a uma ênfase na técnica ou no pensamento guiado por fórmulas. De fino técnica como alguma coisa que pode ser usada em lugar do cérebro, e as escolas de negócios tornaram-se especialistas em cursos que oferecem técnicas - por exemplo, técnicas de enriquecimento de recursos humanos ou model os de portifólio para recursos financeiros. Veja, não estou dizendo que as técnicas não são importantes para a administração; estou querendo chamar a atenção para o fato de que elas devem ser cuidadosamente usadas, e considerando o contexto. $\mathrm{Ou}$ seja, as técnicas não devem ser usadas indiscriminadamente por pessoas que, ansiosas, recorrem a elas para compensar sua falta de experiência pessoal. Vocês já devem ter ouvido a famosa regra da ferramenta: dê a alguém um martel o etudo para ela vai parecer com um prego. Pois bem, os programas de MBA estão dando a seus estudantes tantos martel os que muitas organizações estão se parecendo com uma cama de pregos.

\section{Sabemos que o senhor tem estado à frente de uma iniciativa, na McGill, que procura oferecer o produto certo para as pessoas certas, ou seja, fornecer às pessoas que exercem, efetivamente, funções de liderança o ti po de conhecimento e reflexão sobre suas próprias práticas. Como funciona essa iniciativa? \\ A premissa do International Masters in Practicing Mana-} gement (IMPM) é fazer exatamente o que eu disse: tornar pessoas, que já são líderes, em líderes ainda meIhores. Queremos que essas pessoas sejam enviadas e patrocinadas por suas empresas. Elas permanecem na McGill por apenas duas semanas de cada vez em diversos módulos, de modo que elas permanecem traba-
Ihando normalmente. Nós as queremos no trabalho, como líderes, e então podemos focar a aprendizagem na reflexão de suas próprias atividades gerenciais. Trazemos os conceitos eas idéias, casos e teorias; elas trazem sua experiência. A idéia é focar 0 máximo de aprendizagem possível sobre suas próprias experiências. Desse modo, a idéia que entendo ser promissora é usar a experiência dos líderes, e não apenas o currículo dos professores, fato que entendo ocorrer hoje na maior parte das escolas de negócio ao redor do mundo. 0 foco dessas escolas deve ser na geração de insights, e não no rigor, tampouco na relevância.

Em um artigo recentemente postado em seu site, intitulado "Como a produtividade matou as empresas americanas", o senhor faz uma pesada crítica à prioridade que as empresas dos EUA têm dado ao mercado financei ro em detrimento de funcionári os, crescimento sustentável e mesmo dos clientes. $\mathbf{O}$ senhor poderia nos detal har seu argumento?

No artigo a que você faz menção, defendo que a produtividade tem destruído as empresas americanas. Isso porque temos de qualificar essa produtividade. Trata-se na verdade de ganhos de produtividade no mercado de capitais. Desse modo, entendo que muitos dos ganhos de produtividade sejam perdas de produtividade. Para compreender isso imagine que você seja o primeiro homem de uma grande empresa norte-americana que deseje fazer o 
máximo de dinheiro da forma mais rápida possível para sua companhia e, claro, para você mesmo. Faça o seguinte: demita todo mundo e vá ao mercado de ações, à Bolsa. As horas de trabalho, e seus custos, desaparecem ao mesmo tempo em que as vendas continuam crescendo. Vocêsó precisa do incentivo para cortar preços a fim de desembaraçar as ações de sua empresa. Então, a produtividade dispara enquanto você está fazendo caixa - até, é claro, a Bolsa quebrar. Portanto, "valor ao acionista" não tem nada a ver com o val or de uma empresa, quanto mais com qualquer valor humano. É um eufemismo para elevar o preço das ações de uma empresa 0 mais rapidamente possível.

\section{Como isso repercute junto aos principais executivos da empresa, quiçá até mesmo na preparação dos futuros executivos, os quais parecem cada vez mais destinados à miopia do "máxi mo val or da empresa" no mercado de capitais?}

A pressão que os analistas de mercado exercem sobre os presidentes de empresa e sobre os outros altos executivos é no sentido de elevar o valor das ações na Bolsa. Isso faz com que todos mirem na performance mensurável, em vez de nos produtos, serviços ou nos clientes - em outras palavras, no resultado hoje, e não na sustentabilidade de amanhã. A questão éa seguinte: como fazer com que os funcionários dessas empresas focalizem sua atenção na maximização do valor ao acionista quando a maioria deles nunca sequer se depararam com os acionistas, muitos dos quais negociantes diários

Entendo que há pessoas erradas nos programas de MBA. Esses programas parecem atrair pessoas que eu caracterizaria como sendo impacientes, agressivas e interesseiras. Nem todas, mas um número considerável. Esse é um dos problemas com 0 público das escolas de negócio.

que compram as ações pela manhã e as vendem à tarde? A resposta, consistente com a visão econômica da empresa apresentada antes, é: 1) manter uma pessoa, o presidente, responsável pela performance da empresa inteira; 2) motivar essa pessoa com opções de ações e similares; e 3) dar-Ihe carta branca virtual para agir como quiser - e de forma rápida. Claro, existe uma retórica sobre construir culturas corporativas no longo prazo e encorajar o trabalho em equipe etc. Mas, na realidade é exatamente o contrário que ocorre: as organizações centralizam o poder nos seus principais executivos a um nível jamais visto em décadas. 0 mercado financeiro tem de ser atendido, e isso significa adentrar na era da liderança heróica, capaz de fazer com que uma pessoa consiga levar qual quer outra a apresentar uma performance no curto prazo, não importando como.

\section{O que fazer para contornar a situação?}

Sugiro um teste simples: qualquer pessoa que na organização exigisse um pacote de compensação pessoal massivo que o diferenciasse de qualquer outra pessoa na organização, incluindo proteções que não estão disponíveis para ninguém mais, deveria ser impedida de aspirar à palavra "líder". Quantos CEOs de hoje passariam no teste? No mais, questione os economistas ingênuos e analistas superficiais; 0 "val or ao acionista", que mina o valor da empresa bem como os valores humanos; a "governança", usada como desculpa para a centralização do status quo; a "liderança" que equivale à arrogância (hubris); a idéia de que a empresa é uma coleção de "agentes" desvinculados de uma comunidade de membros engajados; e questione, por fim, a obsessão com a mensuração de tudo, que põe a quantidade acima da qualidade.

Carlos Osmar Bertero

Professor do Departamento de Administração Geral e Recursos Humanos da FGV-EAESP

Doutor em Administração pela

Cornell University

E-mail: carlos.bertero@fgv.br

Pedro F. Bendassolli

Professor do Departamento de

Fundamentos Sociais e Jurídicos da FGV-EAESP

Doutor em Psicologia Social pela USP

E-mail: pedro.bendassolli@fgv.br 